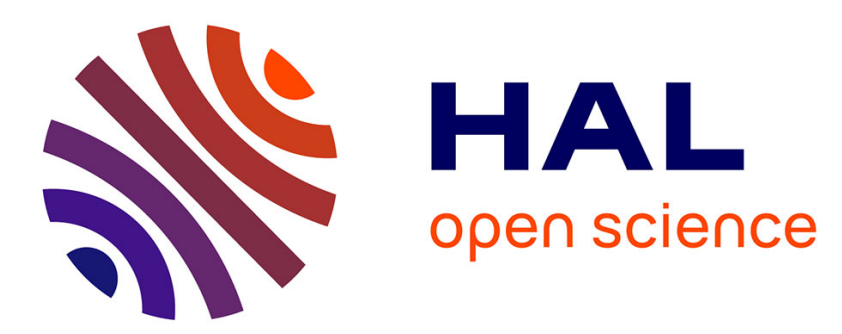

\title{
Carbon nanotubes prepared in situ in a cellular ceramic by the gelcasting-foam method
}

Sébastien Rul, Christophe Laurent, Alain Peigney, Abel Rousset

\section{To cite this version:}

Sébastien Rul, Christophe Laurent, Alain Peigney, Abel Rousset. Carbon nanotubes prepared in situ in a cellular ceramic by the gelcasting-foam method. Journal of the European Ceramic Society, 2003, vol. 23, pp. 1233-1241. 10.1016/S0955-2219(02)00286-8 . hal-00949855

\section{HAL Id: hal-00949855 \\ https://hal.science/hal-00949855}

Submitted on 20 Feb 2014

HAL is a multi-disciplinary open access archive for the deposit and dissemination of scientific research documents, whether they are published or not. The documents may come from teaching and research institutions in France or abroad, or from public or private research centers.
L'archive ouverte pluridisciplinaire HAL, est destinée au dépôt et à la diffusion de documents scientifiques de niveau recherche, publiés ou non, émanant des établissements d'enseignement et de recherche français ou étrangers, des laboratoires publics ou privés. 


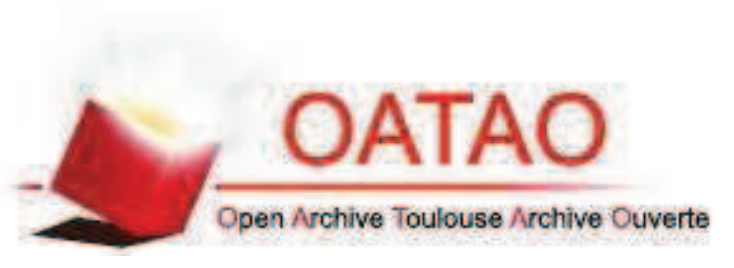

\section{Open Archive Toulouse Archive Ouverte (OATAO)}

OATAO is an open access repository that collects the work of Toulouse researchers and makes it freely available over the web where possible.

This is an author-deposited version published in: http://oatao.univ-toulouse.fr/ Eprints ID: 10449

To link to this article : DOI:10.1016/S0955-2219(02)00286-8

URL : http://www.sciencedirect.com/science/article/pii/S0955221902002868

\section{To cite this version:}

Rul, Sébastien and Laurent, Christophe and Peigney, Alain and Rousset, Abel Carbon nanotubes prepared in situ in a cellular ceramic by the gelcasting-foam method. (2003) Journal of the European Ceramic Society, vol. 23 ( $\mathrm{n}^{\circ}$ 8). pp. 1233-1241. ISSN 0955-2219 


\title{
Carbon nanotubes prepared in situ in a cellular ceramic by the gelcasting-foam method
}

\author{
S. Rul, Ch. Laurent*, A. Peigney, A. Rousset \\ CIRIMAT UMR CNRS 5085, Centre Interuniversitaire de Recherche et d'Ingénierie des Matériaux, \\ Université Paul-Sabatier, 31062 Toulouse cedex 4, France
}

\begin{abstract}
The synthesis of carbon nanotubes from an oxide solid solution foam is reported for the first time. A foam of $\mathrm{Mg}_{0.9} \mathrm{Co}_{0.1} \mathrm{Al}_{2} \mathrm{O}_{4}$ solid solution is prepared by the gelcasting-foam method using notably mono- and di-functional acrylate monomers. Using a surfactant in the alkylpolyglucoside family allows to prevent structure changes in the foam before the onset of polymerisation. The wet ceramic foam is dried in air, producing a foam with an open porosity. Total porosity is equal to about $98 \%$ and the diameter of the pores is in the range 25-300 $\mu \mathrm{m}$, about $90 \%$ being smaller than $200 \mu \mathrm{m}$. The $\mathrm{Mg}_{0.9} \mathrm{Co}_{0.1} \mathrm{Al}_{2} \mathrm{O}_{4}$ foam is reduced in $\mathrm{H}_{2}-\mathrm{CH}_{4}$ atmosphere, giving rise to a CNTs- $\mathrm{Co}-\mathrm{MgAl}_{2} \mathrm{O}_{4}$ composite foam. Using the foam instead of the corresponding powder allows a fourfold increase in the production of carbon nanotubes, more than $95 \%$ of which have only $1(70 \%)$ or 2 walls.
\end{abstract}

Keywords: Carbon nanotubes; Foams; Gelcasting; $\mathrm{MgAl}_{2} \mathrm{O}_{4}$; Nanocomposites

\section{Introduction}

Theoretical and experimental studies on carbon nanotubes (hereafter noted as CNTs) have revealed their exceptional mechanical properties ${ }^{1-3}$ and interesting electrical characteristics such as a metallic or semiconducting behaviour. ${ }^{4,5}$ Another important features of CNTs are a very high aspect ratio (5000-50000) and high specific surface area $\left(1315 \mathrm{~m}^{2} / \mathrm{g}\right.$ for single-walled $\mathrm{CNTs}^{6}$ ). Thus CNTs could advantageously substitute carbon fibres in composites, as reinforcing elements and also in order to provide some degree of electrical conductivity to otherwise insulating materials.

The present laboratory has reported the synthesis of composite powders containing well-dispersed CNTs by the selective reduction in $\mathrm{a}_{2}-\mathrm{CH}_{4}$ atmosphere of solid solutions such as $\mathrm{Al}_{2-2 x} \mathrm{Fe}_{2 x} \mathrm{O}_{3},{ }^{7} \mathrm{Mg}_{1-\mathrm{y}-\mathrm{z}} \mathrm{M}_{y} \mathrm{M}_{z}{ }_{z} \mathrm{Al}_{2} \mathrm{O}_{4}$ $\left(\mathrm{M}, \mathrm{M}^{\prime}=\mathrm{Fe}, \mathrm{Co}, \mathrm{Ni}\right)^{8}$ and $\mathrm{Mg}_{1-\mathrm{t}} \mathrm{Co}_{\mathrm{t}} \mathrm{O} .{ }^{9}$ Very small transition metal (or alloy) nanoparticles are formed upon reduction and the decomposition of $\mathrm{CH}_{4}$ over these pristine nanoparticles prevents their further growth and

\footnotetext{
* Corresponding author. Tel.: + 33-5-61-55-61-22; fax : + 33-5-6155-61-63.

E-mail address: laurent@ chimie.ups-tlse.fr (Ch. Laurent).
}

produces CNTs. There is a very strong proportion of single- and double-walled CNTs (SWNTs and DWNTs, respectively) compared with other forms of carbon in the so-obtained CNT-metal-oxide powders. Dense CNT$\mathrm{Fe}-\mathrm{Al}_{2} \mathrm{O}_{3}, \mathrm{CNT}-\mathrm{Fe} / \mathrm{Co}-\mathrm{MgAl}_{2} \mathrm{O}_{4}$ and $\mathrm{CNT}-\mathrm{Co}-\mathrm{MgO}$ nanocomposites have been prepared by hot-pressing ${ }^{10,11}$ and the CNTs have been aligned by hot-extrusion, producing an anisotropic electrical conductivity. ${ }^{12}$

It may be desirable to increase the quantity of CNTs in the materials. A study on the influence of the specific surface area of the starting solid solution ${ }^{13}$ revealed that increasing it is beneficial provided it reflects a higher surface porosity rather than a higher geometrical surface (smaller grains). Indeed, a higher packing of the oxide grains is achieved in the latter case, which proved detrimental to the CNTs quantity. Thus, the aim of the present work is to prepare a porous oxide solid solution with a low packing in order to get a large enough potentially active surface area and also maintain free space that will allow a good diffusion of $\mathrm{CH}_{4}$.

Porous ceramics, known as reticulate ceramics or ceramic foams, are used in applications such as hot-gas filtration and catalysts support in the environment, aerospace and electronics fields. ${ }^{14}$ Foams can be prepared by several routes including the gelcasting-foam 
method $^{15-18}$ which derives from the gelcasting process used in the preparation process of dense ceramics. ${ }^{19,20}$ In this method, a foam is created in an aqueous suspension of ceramic powder by a vigorous mechanical stirring and is stabilised by the in situ polymerization of organic monomers. After removal from the mould and drying, the foam is fired in air in order to completely burn the remaining organics. Monomer systems have been studied in detail by other researchers. ${ }^{18,21}$ In addition to the monomer, a surfactant, known as a foaming agent, is often necessary to generate a stable foam. ${ }^{22}$ These organic molecules, dissolved or dispersed in a solvent, possess a hydrophilic moiety or polar part, and hydrophobic moiety or non-polar part that are adsorbed preferentially at the gas/liquid interface. By bubbling a gas through the suspension or by vigorous stirring, it is possible to increase the superficial area at the gas/liquid interface. This extra surface is then available for the adsorption of the foaming agent present in the liquid. Once adsorbed on the surface, these surfaceactive molecules produce a significant lowering of the surface tension thus favouring the foaming process. Surfactants are generally classified into four categories depending upon the nature of the adsorbing moiety: anionic, cationic, zwitterionic or non-ionic. Non-ionic surfactants have a weaker foaming capacity when compared to ionic surfactants, but are preferred for the gelcasting-foam method ${ }^{22}$ because ionic surfactants decrease the stability of the suspension. Moreover, nonionic surfactants have the advantage of being stable and active in a wide $\mathrm{pH}$ range and are easily eliminated by simple calcination thus reducing the risk of contamination. There exist two families of non-ionic surfactants, namely, alkylpolyoxyethylenes (APE) and alkylpolyglucosides (APG), derived from glucose. As noted by Nilsson, ${ }^{23}$ APG have been synthesised for the first time in $1938,{ }^{24}$ but have attracted interest for only a few years.

In the present paper, we report for the first time the synthesis of CNTs from an oxide solid solution foam. Firstly, tests were carried out on different non-ionic surfactants so as to determine essential parameters such as the foaming capacity and the stability of the foam. Based on the results of these experiments, a particular surfactant was chosen and a foam of $\mathrm{Mg}_{0.9} \mathrm{Co}_{0.1} \mathrm{Al}_{2} \mathrm{O}_{4}$ was prepared. Finally, CNTs were grown from the $\mathrm{Mg}_{0.9} \mathrm{Co}_{0.1} \mathrm{Al}_{2} \mathrm{O}_{4}$ foam and from the corresponding powder. It is notably shown that using the foam instead of the powder allows a four-fold increase in the production of CNTs.

\section{Experimental procedure}

\subsection{Choice of the foaming agent}

Three APE (G3300B (ICI, UK), IGEPAL CA630 (Sigma Aldrich, Germany) and Triton X114 (Sigma
Aldrich, Germany)) and two APG (Simulsol SL26 (Seppic, France) and Oramix NS10 (Seppic, France)) surfactants were tested as foaming agents (Table 1). Aqueous solutions of the surfactants $(0-50 \mathrm{~g} / \mathrm{l})$ were prepared. A procedure in three steps was followed in order to chose a surfactant for later studies. Firstly, the evolution of the foaming capacity of each solution was observed. The foaming capacity is still a poorly defined concept which depends on the method used to evaluate it, but which will allow to determine which surfactant shows the maximum foaming. A foam was generated in a graduated cylindrical vessel by vigorously stirring the solutions at room temperature (RT). Stirring was stopped after 5 min and the foam volume was measured. This was done three times for each solution. From these results, the concentration for which the maximum volume is obtained $\left(C_{\max }\right)$ was evaluated for each surfactant. Secondly, each solution at the so-determined $C_{\max }$ was stirred at room temperature in a graduated vessel and the vessel was then transferred to a bainmarie maintained at $70{ }^{\circ} \mathrm{C}$, which is the temperature that will be used later in the study for the polymerisation of the appropriate monomers. The evolution of the foam at $70{ }^{\circ} \mathrm{C}$ was observed and the time during which it is stable was measured. A foaming agent was then chosen based on the previous two criteria (maximum foaming and foam stability). Thirdly, the foaming of a solution at $C_{\max }$ of this surfactant was again measured (as in the first test) but using different temperatures between RT and $70{ }^{\circ} \mathrm{C}$. The temperature at which the maximum foaming was observed was chosen for later studies.

\subsection{Elaboration of a ceramic foam by the gelcasting foam method}

A powder of $\mathrm{Mg}_{0.9} \mathrm{Co}_{0.1} \mathrm{Al}_{2} \mathrm{O}_{4}$ solid solution was prepared by the nitrate-urea combustion technique ${ }^{25}$ as reported elsewhere. ${ }^{8,26}$ The combustion product was ground manually to a powder. This powder is made up of primary grains smaller than $100 \mathrm{~nm}$ but strongly aggregated, which required attrition-milling in order to reduce the aggregate size to less than $1 \mu \mathrm{m}$. Twenty grams of the powder were dispersed in deionised water $(28 \mathrm{wt} . \%$ of dry matter) containing 0.7 wt. $\%$ of dispersant [Duramax

Table 1

The surfactants used in this work

\begin{tabular}{lll}
\hline Usual name & Surface-active molecule & Family \\
\hline G3300B & - & APE \\
IGEPAL CA630 & Polyoxyethyleneisooctylphenyl ether & APE \\
Triton X114 & Polyoxyethyleneisooctylcyclohexyl ether & APE \\
Simulsol SL26 & Dodecylglucoside & APG \\
Oramix NS10 & Decylglucoside & APG \\
\hline
\end{tabular}

APE, alkylpolyoxyethylenes, APG, alkylpolyglucoside. 
D-3005(Rohm and Haas, France)] and the resulting slurry was attrition-milled (2000 rpm) for $135 \mathrm{~min}$, using a Nylon vessel and rotor and yttria-stabilised zirconia balls (tetragonal form) $1 \mathrm{~mm}$ in diameter. This however produced a mild contamination by $\mathrm{ZrO}_{2}$ particles about $1 \mu \mathrm{m}$ in size. After attrition-milling, the zirconia balls were separated by rinsing in deionised water and filtering the slurry which was then partly evaporated so as to obtain a volume of $100 \mathrm{ml}$. Another batch was fully dried and calcined at $500{ }^{\circ} \mathrm{C}$ to eliminate nylon contamination, producing a powder that will be used for comparison with the foam.

The complete process for the synthesis of a ceramic foam containing CNTs is summarised in Fig. 1. A monomer solution was prepared by mixing a monofunctional monomer [2-hydroxyethyl methacrylate, noted HEMA, $3.8 \mathrm{~g}$ ) from which the polymeric network will be made up, a di-functional monomer (40\% aqueous solution of poly(ethylene glycol 1000) dimethacrylate, noted $\left.\mathrm{PEG}_{1000} \mathrm{DMA}, 10.2 \mathrm{~g}\right]$ which will serve as a reticulating agent (crosslinker), and potassium persulphate $\left(\mathrm{K}_{2} \mathrm{~S}_{2} \mathrm{O}_{8}, 0.0936 \mathrm{~g}\right)$ as an initiator. The monomer solution was added to the ceramic slurry. The resulting slurry was well homogenised and was poured into a cylindrical mould in which the foaming agent had been previously introduced $\left(0.4 \mathrm{~g}\right.$, in order to obtain $C_{\max }$ in the final slurry). The mould was closed and transferred to a bain-marie maintained at $70{ }^{\circ} \mathrm{C}$. Nitrogen was flowed for about $3 \mathrm{~min}$ in order to eliminate oxygen, which can inhibit polymerization. ${ }^{27}$ The slurry was vigorously agitated and foaming occurred immediately. The maximum volume was obtained after stirring for about $5 \mathrm{~min}$. After the polymerisation of the acrylic monomers which stabilised the foam (duration about $90 \mathrm{~min}$ ), air was introduced and the mould was left to cool down at RT and then placed for $6 \mathrm{~h}$ in an oven at $50{ }^{\circ} \mathrm{C}$. After release from the mould, the foam was placed for $24 \mathrm{~h}$ in an oven at $100{ }^{\circ} \mathrm{C}$ for complete drying. Finally, a calcination in air was performed at $400{ }^{\circ} \mathrm{C}$ in order to burn all organic materials, producing the desired $\mathrm{Mg}_{0.9} \mathrm{Co}_{0.1} \mathrm{Al}_{2} \mathrm{O}_{4}$ solid solution foam.

\subsection{Synthesis of carbon nanotubes}

The $\mathrm{Mg}_{0.9} \mathrm{Co}_{0.1} \mathrm{Al}_{2} \mathrm{O}_{4}$ powder and foam were reduced in a $\mathrm{H}_{2}-\mathrm{CH}_{4}$ atmosphere $\left(18 \mathrm{~mol}_{0} \mathrm{CH}_{4}, 1000{ }^{\circ} \mathrm{C}\right)$. The gas flow was dried on $\mathrm{P}_{2} \mathrm{O}_{5}$ and its composition was set up using massflow controllers. The flow rate was fixed at $250 \mathrm{sccm}$. Cobalt particles a few nanometres in diameter are produced, both inside and at the surface of each grain of the powder. The surface metal particles catalyse the decomposition of $\mathrm{CH}_{4}$ thus producing the CNTs as described in previous papers. ${ }^{7-9}$

\subsection{Characterisation}

The specific surface areas of the powder and foam were measured by the BET method using $\mathrm{N}_{2}$ adsorption at liquid $\mathrm{N}_{2}$ temperature. A Micromeritics Flowsorb II 2300 apparatus that gives a specific surface area value from one point (i.e. one adsorbate pressure) and requires calibration was used. We determined that the

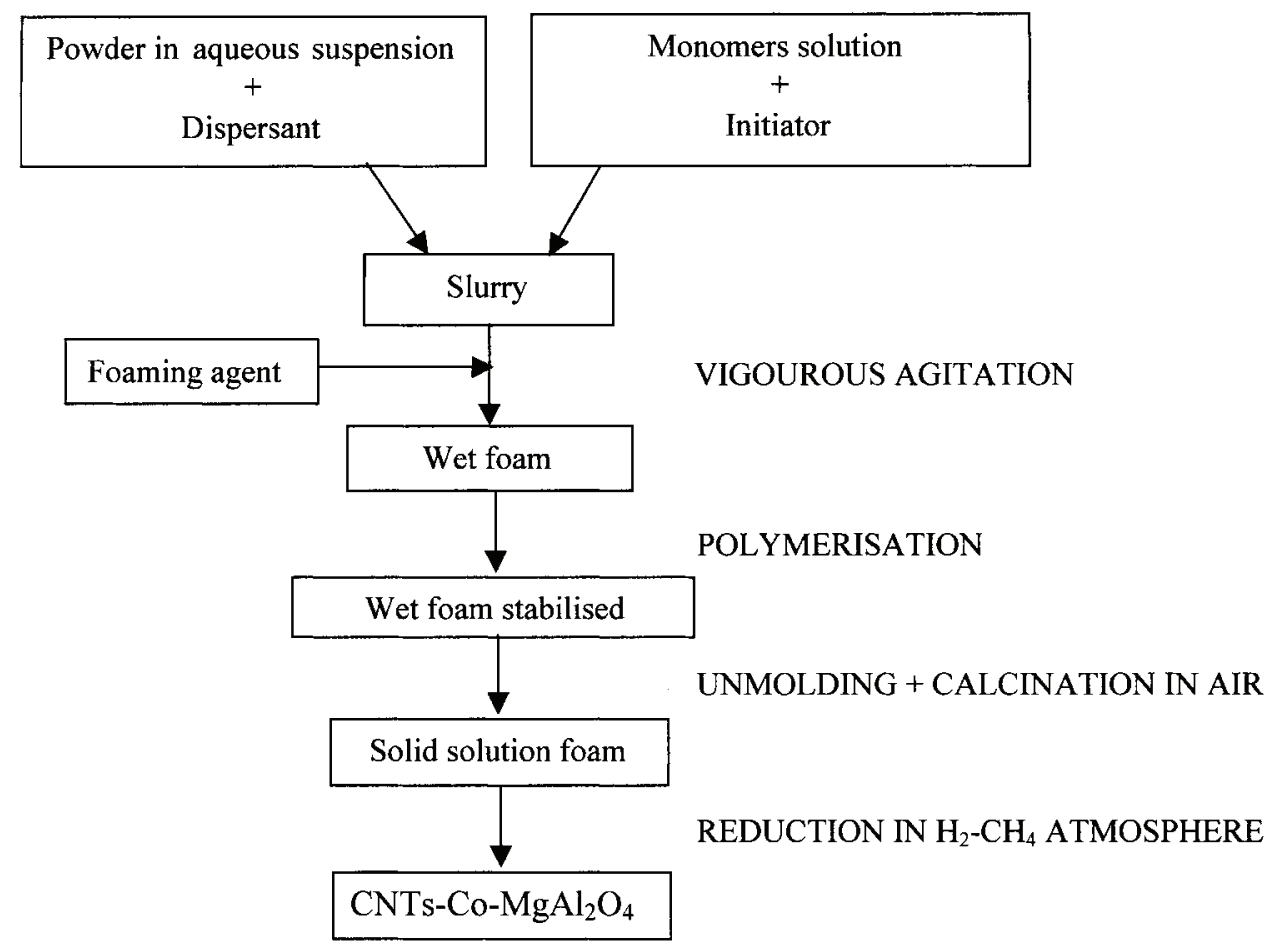

Fig. 1. Flow-chart of the complete process for the synthesis of a ceramic foam containing CNTs. 
reproducibility of the results was in the $\pm 3 \%$ range. The density of the ceramic foam was estimated from the mass and dimensions of cylindrical or cubic samples machined in the original body. The ceramic foam was observed by scanning electron microscopy (SEM) and the pore size and pore size distribution were determined from the SEM images. The carbon content in the reduced specimens was determined by flash combustion. The quantity of CNTs was evaluated using specific surface area measurements as detailed elsewhere. ${ }^{6,7}$ The CNTs were observed using high resolution transmission electron microscopy (HREM).

\section{Results and discussions}

\subsection{Choice of the surfactant}

The evolution of the foaming capacity versus the concentration of the different surfactants is shown in Fig. 2. For all surfactants, the foaming capacity strongly increases until it reaches a maximum, then decreases regularly, reaching a plateau in the case of IGEPAL CA630. Increasing the surfactant concentration favours its adsorption at the gas/liquid interface and a decrease of the surface tension which will favour foaming. For a certain concentration $C_{\max }$, the surface tension is minimal and foaming is maximum. $C_{\max }$ is close to the critical micelle concentration (CMC), which represents the minimal surfactant quantity to reach the minimal surface tension. For higher concentrations, the
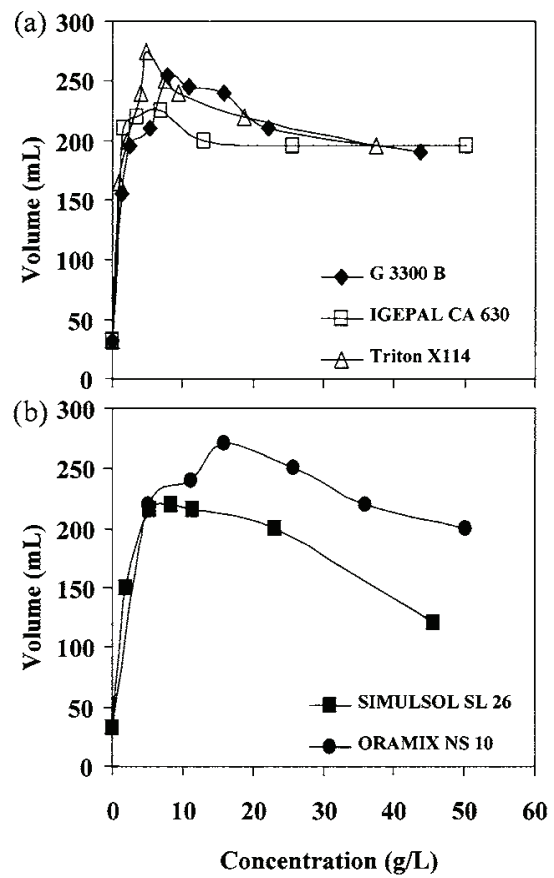

Fig. 2. Evolution of the foaming capacity of the different surfactants versus the concentration in deionised water. The lines are guides to the eye. surface tension remains minimal, but the presence of more surfactant will generate an increase in the viscosity of the system, which will inhibit the foaming effect. Because of medium's viscosity, $C_{\max }$ does not correspond precisely to the CMC.

The maximum volume and the corresponding concentration $C_{\max }$ are reported in Table 2. Triton X114 and Oramix NS10 appear to provide a slightly higher maximum foam-volume than the other surfactants. This maximum is obtained for $C_{\max }$ in the range $4.5-8.5 \mathrm{~g} / 1$, except for Oramix NS10 for which $C_{\max }$ is markedly higher $(25.8 \mathrm{~g} / \mathrm{l})$.

A foam was prepared for each solution at $C_{\max }$ and the vessel was then transferred to a bain-marie maintained at $70{ }^{\circ} \mathrm{C}$. The evolution of the foam at $70{ }^{\circ} \mathrm{C}$ was observed. It is desirable that the foam does not evolve before being stabilised by the polymerisation of the acrylate monomers, whose idle time is 7-8 min. Two phenomena are to be observed: the gravitational drainage (separation of the system in two phases) and the foam disappearance by various macroscopic phenomena (Ostwald ripening, Van der Waals forces, electrostatic forces, steric forces, etc.). The measured times are reported in Table 3. Drainage is faster for the APE (1-5 min) than for the APG (8-10 min) surfactants. After drainage, the foam evolves notably by Ostwald ripening who tends to make the small bubbles disappear to the profit of the larger ones. For the APE surfactants, ripening starts immediately after drainage end, resulting in a complete disappearance of the foam in 7-20 min. By contrast, foams prepared from the APG surfactants

Table 2

The maximum foam volume $( \pm 10 \mathrm{ml})$ and the corresponding concentration $C_{\max }$ for the different surfactants

\begin{tabular}{llc}
\hline Surfactant & $\begin{array}{l}\text { Maximum foam } \\
\text { volume }(\mathrm{ml})\end{array}$ & $\begin{array}{r}\text { Cmax } \\
(\mathrm{gl}-1)\end{array}$ \\
\hline G3300B & 230 & 7.8 \\
IGEPAL CA630 & 225 & 6.7 \\
Triton X114 & 275 & 4.7 \\
Simulsol SL26 & 225 & 8.3 \\
Oramix NS10 & 255 & 15.8 \\
\hline
\end{tabular}

Table 3

The stability of the foam prepared with the different surfactants (all times are in minutes) at the concentration allowing maximum volume

\begin{tabular}{llllc}
\hline Surfactant & $\begin{array}{l}\text { Drainage } \\
\text { beginning }\end{array}$ & $\begin{array}{l}\text { Drainage } \\
\text { end }\end{array}$ & $\begin{array}{l}\text { Beginning of } \\
\text { volume loss }\end{array}$ & $\begin{array}{l}\text { Disappearance } \\
\text { of foam }\end{array}$ \\
\hline G3300B & 1.5 & 5 & 5 & 20 \\
IGEPAL CA630 & 0.3 & 1 & 1 & 7 \\
Triton X114 & 0.3 & 1 & 1 & 8 \\
Simulsol SL26 & 2 & 10 & 30 & 90 \\
Oramix NS10 & 1.5 & 8 & 15 & 30 \\
\hline
\end{tabular}


are stable for some time (7-20 min) after drainage end. Furthermore, the subsequent evolution is much slower in the case of Simulsol SL26 (90 min. for complete disappearance of the foam). These phenomena could be explained by the different behaviour of APE and APG versus the temperature. Indeed, when the temperature is raised to $70{ }^{\circ} \mathrm{C}$, the APE surfactants lose any solubility because this temperature is higher than their so-called temperature of disorder. Thus, the surfactant has a tendency to be desorbed, the surface tension increases and the foam loses any stability. On the other hand, the APG solubility increases with an increase in temperature $^{23}$ and thus the APG preserve a good solubility at $70{ }^{\circ} \mathrm{C}$, which result in a foam with better stability.

At room temperature, Oramix NS10 provides a higher foaming volume but for a markedly higher concentration than Simulsol SL26 (Table 2). Moreover, the foam obtained with the latter surfactant is much more stable. Thus, Simulsol SL26 was chosen as foaming agent for the studies presented in the following sections.

The influence of the foaming temperature $\left(\mathrm{RT}-70{ }^{\circ} \mathrm{C}\right)$ on the maximum foam volume using an aqueous solution of Simulsol SL26 at $C_{\max }(8.3 \mathrm{~g} / 1)$ is reported in Fig. 3. The volume regularly increases (up to $285 \mathrm{ml}$ ) with the temperature. Indeed, increasing the temperature will weaken the interactions between surfactant molecules and thus favour the surfactant-water interactions, resulting in a better foaming.

\subsection{Preparation of a ceramic foam by the gelcasting foam method}

The slurry containing the powder and all desired reagents was transferred into the mould maintained at $70{ }^{\circ} \mathrm{C}$ and nitrogen was flowed for about $3 \mathrm{~min}$. The slurry was vigorously agitated for $6 \mathrm{~min}$, producing a four-fold increase in volume (from 45 to $180 \mathrm{ml}$ ), which is comparable to values found in the literature for foams generated at room temperature. ${ }^{22}$ After release from the

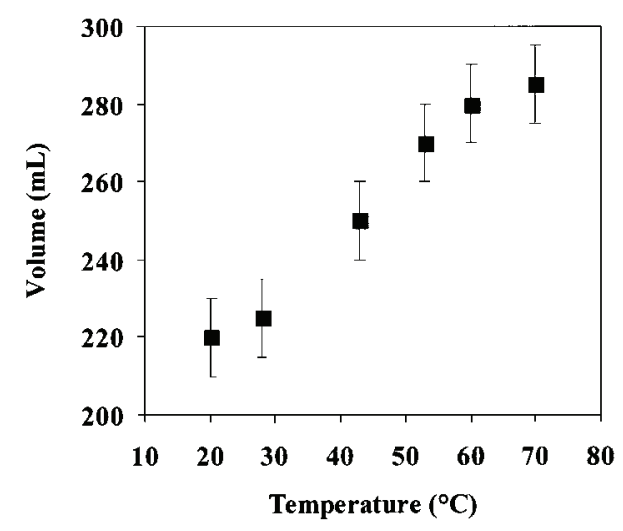

Fig. 3. Foam volume versus the foaming temperature using an aqueous solution of Simulsol SL26 at $C_{\max }(8.3 \mathrm{~g} / 1)$. mould and drying, some cracks were observed in the foam, probably because of a too rapid drying. A humidity-controlled chamber could be used to avoid this. ${ }^{28}$ Heat-treatment in air at $400{ }^{\circ} \mathrm{C}$ allowed to burn all organic materials. A moderate temperature was chosen in order to sinter sufficiently so that the foam can be manipulated without collapsing, while preserving a high specific surface area $\left(44 \mathrm{~m}^{2} / \mathrm{g}\right)$ in order to favour the reduction of the cobalt ions in the subsequent $\mathrm{H}_{2}-\mathrm{CH}_{4}$ treatment. The foam density was found equal to $0.192 \mathrm{~g} / \mathrm{cm}^{3}$, which corresponds to a porosity of $98 \%$. SEM images (Fig. 4) of the solid solution foam reveal a highly porous microstructure (Fig. 4a), with a communicating porosity. Indeed, holes probably arising from the gaseous emissions during calcination can be observed in the pore walls (Fig. 4b). The diameter of the pores lies between 25 and $300 \mu \mathrm{m}$, about $90 \%$ being smaller than or equal to $200 \mu \mathrm{m}$ (Fig. 5). This shows that the surfactant efficiently stabilised the foam before the polymerisation. Pores ranging between 30 and 600 $\mu \mathrm{m}$ for idle time of $30 \mathrm{~s}$ after foam generation have been reported. ${ }^{17,29,30}$

\subsection{Synthesis of carbon nanotubes}

The powder and the foam were reduced in $\mathrm{H}_{2}-\mathrm{CH}_{4}$ atmosphere. The carbon content $C_{\mathrm{n}}$ in the so-obtained CNT-metal-spinel powder and foam was found equal to $1.16 \pm 0.02$ and $4.44 \pm 0.09$ wt. $\%$, respectively. As
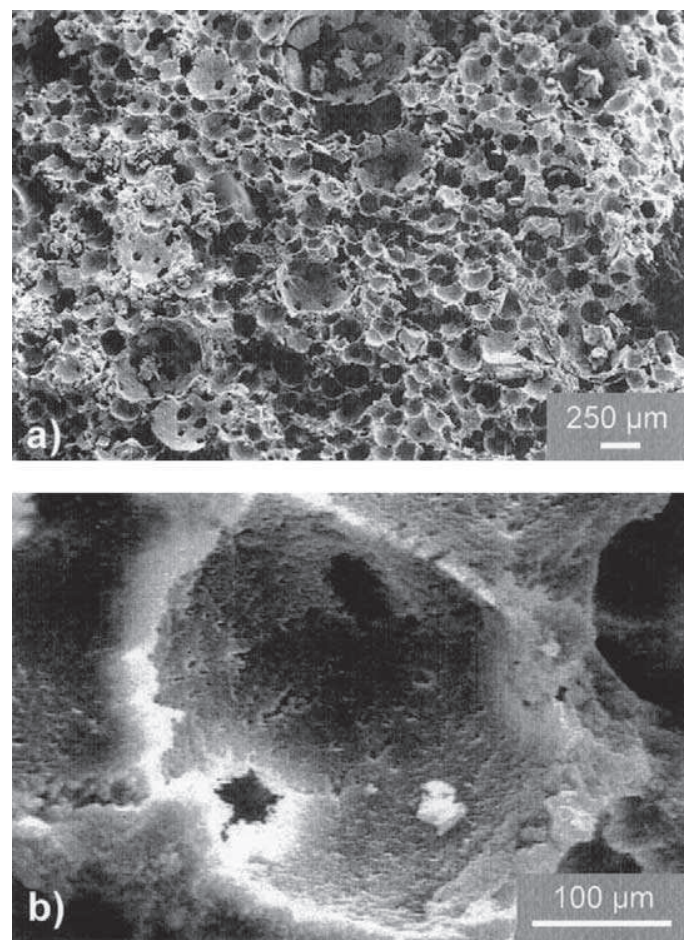

Fig. 4. SEM images of the solid solution foam. 


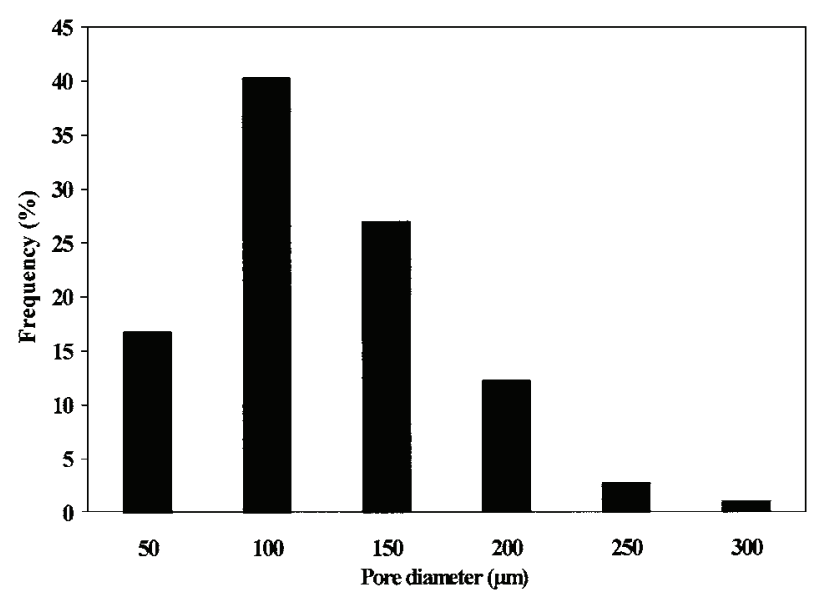

Fig. 5. Pore diameter distribution (482 pores measured on SEM images).

reported in previous papers, ${ }^{7-9}$ the quantity of CNTs is represented by the difference in specific surface area between the reduced specimen (powder or foam) and the same specimen subsequently oxidised in air $\left(700^{\circ} \mathrm{C}\right.$, $3 \mathrm{~min}$ ) in order to burn all carbon. This value, noted $\Delta S$, was found equal to $6 \pm 1$ and $27 \pm 2 \mathrm{~m}^{2} / \mathrm{g}$ for the powder and foam, respectively. Thus, reducing the solid-solution foam produces a four-fold increase in the production of CNTs. This is partly due to the accessible porosity present in the foam, since the specific surface area of the starting foam $\left(44 \mathrm{~m}^{2} / \mathrm{g}\right)$ is only about twice higher than that of the corresponding starting powder $\left(23 \mathrm{~m}^{2} / \mathrm{g}\right)$. The ratio $\Delta S / C_{\mathrm{n}}$ represents the overall quality of carbon in the specimen, a higher figure for $\Delta S / C_{\mathrm{n}}$ denoting more carbon in tubular form and/or CNTs with less walls and/or a smaller average tube diameter. ${ }^{6}$ Relatively similar values are calculated for the powder and foam $\left(510 \pm 105\right.$ and $601 \pm 50 \mathrm{~m}^{2} / \mathrm{g}$, respectively), showing that the carbon quality is not affected when starting with a solid-solution foam.

SEM images (Fig. 6) of the CNT-Co- $\mathrm{MgAl}_{2} \mathrm{O}_{4}$ foam reveal the presence of long, flexible filaments, which are known $^{7-9,11,13}$ to be CNTs bundles, extremely well dispersed as a web-like network between the matrix agglomerates. The diameter of the bundles is not larger than $30 \mathrm{~nm}$ and no thick filaments are observed, indicating the chemical homogeneity of the starting oxide. Indeed, the presence of thick, short filaments would have indicated the formation of large metal particles upon reduction, thus revealing the presence of cobaltrich areas within the starting oxide. ${ }^{13,31,32}$ A higher magnification image (Fig. 6b) shows that the bundles have a smooth and regular surface and are extensively branched. These results on the quality of the deposited carbon are confirmed by HREM observations (Fig. 7). Typical images show small bundles of CNTs with superimposed cobalt particles (appearing as black dots)
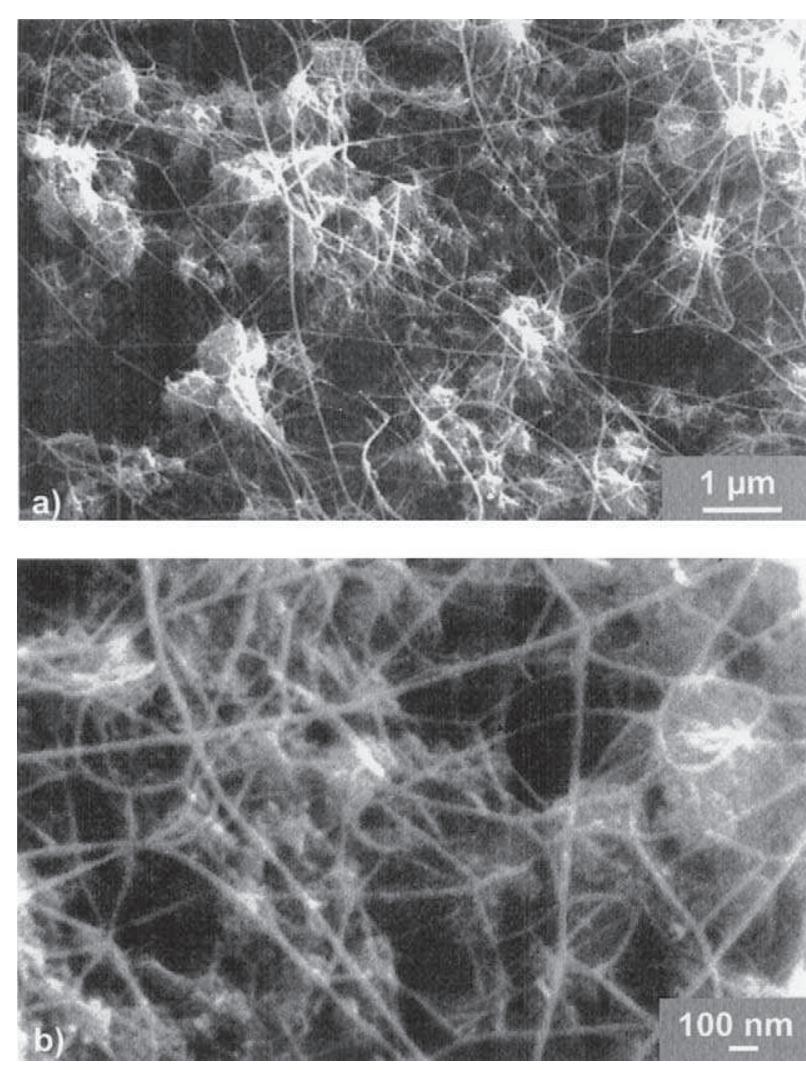

Fig. 6. SEM images of the CNTs- $\mathrm{Co}-\mathrm{MgAl}_{2} \mathrm{O}_{4}$ foam.

probably covered by a few graphene layers (Fig. 7a), entangled individual SWNTs (Fig. 7b), SWNTs 2.0, 3.1 and $1.6 \mathrm{~nm}$ in diameter (Fig. 7c-e, respectively) and DWNTs $1.6,3.3$ and 1.9 , and $4.3 \mathrm{~nm}$ in outer diameter (Fig. 7f-h, respectively). The empty closed tip of a SWNT is shown in Fig. 7d. It is noteworthy that no amorphous carbon coating of the CNTs is observed. CNTs with 3-5 walls were very marginally observed. The number of walls as well as the inner and outer diameters of 140 isolated CNTs were measured on HREM images similar to those shown in Fig. 6. More than 95\% of the CNTs have only 1 or 2 walls, about $70 \%$ being SWNTs (Fig. 8a). The average number of walls, which is only a statistical parameter since it is not an integer, is $N_{\mathrm{m}}=1.4$. The inner and outer diameters (Fig. $8 \mathrm{~b}$ ) are in the range $0.5-5 \mathrm{~nm}$. This is similar to what is reported for CNTs prepared by catalytic methods. ${ }^{9,13,33-43}$ As pointed out by Dai et al., ${ }^{35}$ a distribution in tube diameter reflects a mechanism in which the diameter is established by the catalytic particle. Although several mechanisms do exist, theoretical and experimental results show that CNTs are mainly produced by catalyst particles below ca. $3 \mathrm{~nm}$ in diameter, ${ }^{9,33,34,36}$ while larger particles are encapsulated, in good agreement with the present diameter distribution. 

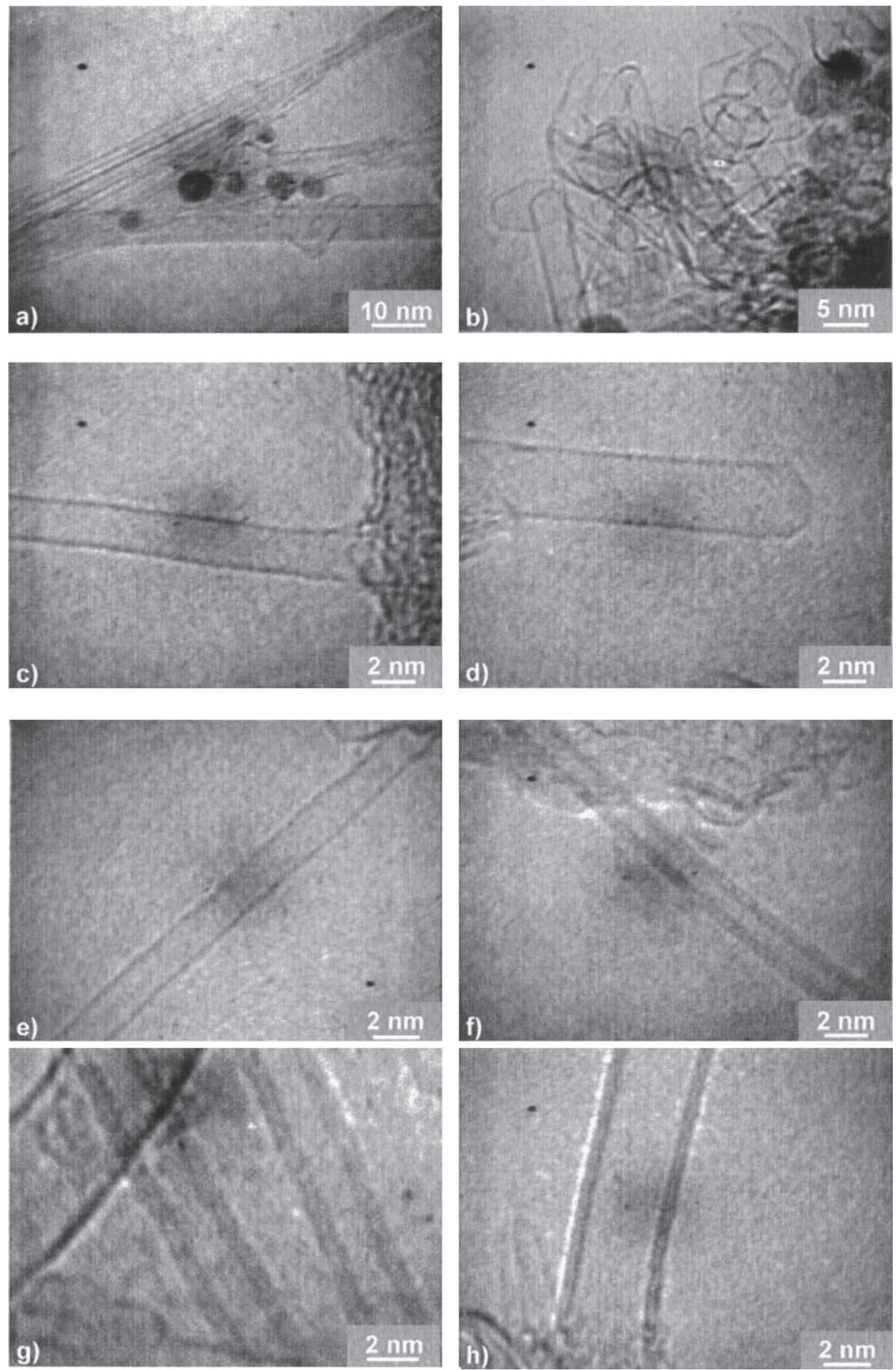

Fig. 7. HREM digital images of typical CNTs prepared from the foam: small bundles of CNTs with superimposed cobalt particles (black dots) probably covered by a few graphene layers (a), entangled individual SWNTs (b), SWNTs (c, d, e) and DWNTs (f, g, h). Note the empty closed tip of a SWNT in $(d)$. 

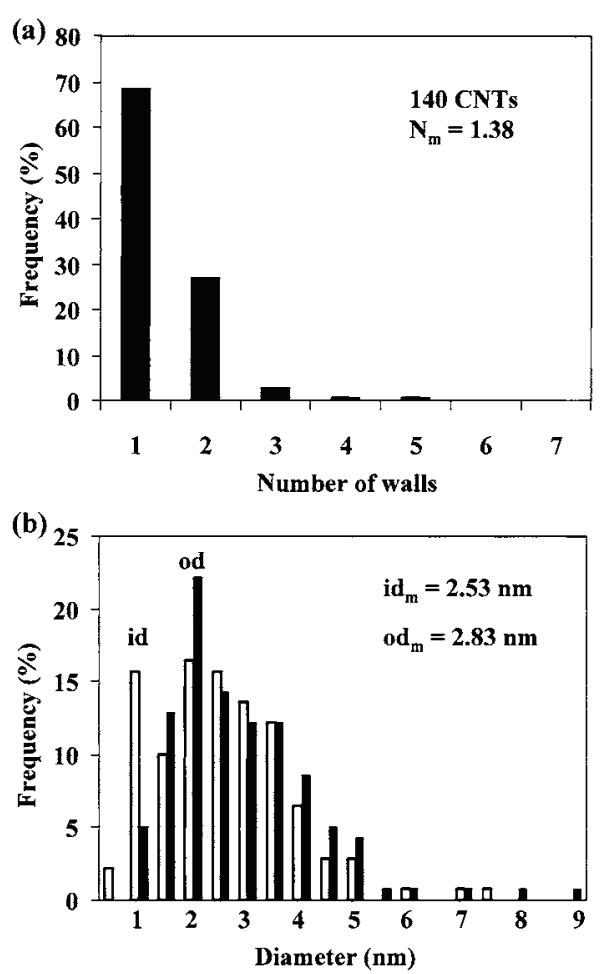

Fig. 8. Distribution of the numbers of walls (a) and of the inner and outer diameters (b) calculated from the observation of 140 CNTs on HREM digital images.

\section{Conclusions}

The synthesis of CNTs from an oxide solid solution foam is reported for the first time. Tests on the foaming capacity and foam stability of different non-ionic surfactants were performed in order to chose a surfactant appropriate for the study. A foam of $\mathrm{Mg}_{0.9} \mathrm{Co}_{0.1} \mathrm{Al}_{2} \mathrm{O}_{4}$ solid solution was then prepared by the gelcasting-foam method using notably mono- and di-functional acrylate monomers. It was found that using a surfactant in the APG family allows to prevent structure changes in the foam before the onset of polymerisation. The wet ceramic foam was dried in air, producing a foam with an open porosity. Total porosity is equal to about $98 \%$ and the diameter of the pores lies between 25 and $300 \mu \mathrm{m}$, about $90 \%$ being smaller than $200 \mu \mathrm{m}$. The $\mathrm{Mg}_{0.9} \mathrm{Co}_{0.1} \mathrm{Al}_{2} \mathrm{O}_{4}$ foam was reduced in $\mathrm{H}_{2}-\mathrm{CH}_{4}$ atmosphere, giving rise to a CNTs- $\mathrm{Co}-\mathrm{MgAl}_{2} \mathrm{O}_{4}$ composite foam. It was shown that using the foam instead of the corresponding powder allows a fourfold increase in the production of CNTs, more than $95 \%$ of which have only 1 or 2 walls and about $70 \%$ being SWNTs. The preparation of dense materials from such composite foams as well as their mechanical and electrical properties will be reported elsewhere.

\section{Acknowledgements}

The authors would like to thank Mr. L. Datas for his assistance in the HREM observations, which have been performed at the Service Commun de Microscopie Electronique à Transmission-Université Paul-Sabatier, and Dr. M. Mauzac and Dr. E. Pérez (IMRCP, UMR CNRS 5623, Université Paul-Sabatier) for their help in the preparation of the foam.

\section{References}

1. Treacy, M. M. J., Ebbesen, T. W. and Gibson, J. M., Exceptionally high Young's modulus observed for individual carbon nanotubes. Nature, 1996, 381, 678-680.

2. Ruoff, R. S. and Lorents, D. C., Mechanical and thermal properties of carbon nanotubes. Carbon, 1995, 33, 925-930.

3. Salvetat, J. P., Briggs, G. A. D., Bonard, J. M., Bacsa, R. R., Kulik, A. J., Stockli, T., Burnham, N. A. and Forro, L., Elastic and shear moduli of single-walled carbon nanotube ropes. Phys. Rev. Lett., 1999, 82, 944-947.

4. Dai, H., Wong, E. W. and Lieber, C. M., Probing electrical transport in nanomaterials: conductivity of individual carbon nanotubes. Science, 1996, 272, 523-526.

5. Ebbesen, T. W., Lezec, H. J., Hiura, H., Benett, J. W., Ghaemi, H. F. and Thio, T., Electrical conductivity of individual carbon nanotubes. Nature, 1996, 382, 54-56.

6. Peigney, A., Laurent, Ch., Flahaut, E., Bacsa, R. R. and Rousset, A., Specific surface area of carbon nanotubes and bundles of carbon nanotubes. Carbon, 2001, 139, 507-514.

7. Peigney, A., Laurent, Ch., Dobigeon, F. and Rousset, A., Carbon nanotubes grown in-situ by a novel catalytic method. J. Mater. Res., 1997, 12, 613-615.

8. Flahaut, E., Govindaraj, A., Peigney, A., Laurent, Ch., Rousset, A. and Rao, C. N. R., Synthesis of single-walled carbon nanotubes using binary $(\mathrm{Fe}, \mathrm{Co}, \mathrm{Ni}$ ) alloy nanoparticles prepared in situ by the reduction of oxide solid solutions. Chem. Phys. Lett., 1999, 300, 236-242.

9. Flahaut, E., Peigney, A., Laurent, Ch. and Rousset, A., Synthesis of single-walled carbon nanotubes- $\mathrm{Co}-\mathrm{MgO}$ composite powders and extraction of the nanotubes. J. Mater. Chem., 2000, 10, 249-252.

10. Laurent, Ch., Peigney, A., Dumortier, O. and Rousset, A., Carbon nanotubes- $\mathrm{Fe}-\mathrm{Al}_{2} \mathrm{O}_{3}$ nanocomposites. Part II : microstructure and mechanical properties of the hot-pressed composites. J. Eur. Ceram. Soc., 1998, 18, 2005-2013.

11. Flahaut, E., Peigney, A., Laurent, Ch., Marlière, Ch., Chastel, F. and Rousset, A., Carbon nanotube-metal-oxide nanocomposites : microstructure, electrical conductivity and mechanical properties. Acta Mater., 2000, 48, 3803-3812.

12. Peigney, A., Flahaut, E., Laurent, Ch., Chastel, F. and Rousset, A., Aligned carbon nanotubes in ceramic-matrix nanocomposites prepared by high-temperature extrusion. Chem. Phys. Lett., 2002, 352, 20-25.

13. Laurent, Ch., Peigney, A., Flahaut, E. and Rousset, A., Synthesis of carbon nanotubes $-\mathrm{Fe}-\mathrm{Al}_{2} \mathrm{O}_{3}$ powders : influence of the characteristics of the starting $\mathrm{Al}_{1.8} \mathrm{Fe}_{0.2} \mathrm{O}_{3}$ oxide solid solution. Mater. Res. Bull., 2000, 35, 1661-1673.

14. Saggio-Woyansky, J., Scott, C. E. and Minnear, W. P., Processing of porous ceramics. Am. Ceram. Soc. Bull., 1992, 71, 1674 1682.

15. Binner, J. G. P., Production and properties of low density engineering ceramic foams. Brit. Ceram. Trans, 1997, 96, 247-249.

16. Sepulveda, P., Gelcasting foams for porous ceramics. Am. Ceram. Soc. Bull., 1997, 76, 61-65. 
17. Sepulveda, P. and Binner, J. G. P., Processing of cellular ceramics by foaming and in situ polymerisation of organic monomers. J. Eur. Ceram. Soc., 1999, 19, 2059-2066.

18. Ortega, F. S., Sepulveda, P. and Pandolfelli, V. C., Monomer systems for the gelcasting of foams. J. Eur. Ceram. Soc., 2002, 22, 1395-1401.

19. Omatete, O. O., Janney, M. A. and Strehlow, R. A., Gel-casting - a new ceramic forming process. Ceram. Bull, 1991, 70, 1641-1649.

20. Omatete, O. O., Janney, M. A. and Nunn, S. D., Gelcasting. from laboratory development toward industrial production. J. Eur. Ceram. Soc., 1997, 17, 407-413.

21. Janney, M. A., Omatete, O. O., Walls, C. A., Nunn, S. D., Ogle, R. J. and Westmoreland, G., Development of low toxicity gelcasting systems. J. Am. Ceram. Soc., 1998, 81, 581-591.

22. Ortega, F. S., Sepulveda, P., Innocentini, M. D. M. and Pandolfelli, V. C., Surfactants, a necessity for producing porous ceramics. Am. Ceram. Soc. Bull., 2001, 80, 37-42.

23. Nilsson, F., Alkylglucosides' physical-chemical properties. Surfactants \& Detergents Inform, 1996, 7, 490-496.

24. Noller, C. R. and Rockwell, W. C., The preparation of some higher alkylglucosides. J. Am. Chem. Soc., 1938, 60, 2076-2077.

25. Kingsley, J. J. and Patil, K. C., A novel combustion process for the synthesis of fine particle of $\alpha$-alumina and related oxide materials. Mater. Lett., 1988, 6, 427-432.

26. Quénard, O., Laurent, Ch., Brieu, M. and Rousset, A., Synthesis, microstructure and oxidation of $\mathrm{Co}-\mathrm{MgAl}_{2} \mathrm{O}_{4}$ and $\mathrm{Ni}-\mathrm{MgAl}_{2} \mathrm{O}_{4}$ nanocomposites powders. Nanostruct. Mater., 1996, 7, 497-507.

27. Landham, R. R., Nahass, P., Leung, D. K., Ungureit, M., Rhine, W. E., Bowen, H. R. and Calvert, P. D., Potential use of polymerisation solvents and dispersants for tape casting of ceramics. Ceram. Bull, 1987, 66, 1513-1516.

28. Prabhakaran, K. and Pavithran, C., Gelcasting of alumina from acidic aqueous medium using acrylic acid. J. Eur. Ceram. Soc., 2000, 20, 1115-1119.

29. Smith, R. T., Sambrook, R. M. and Binner, J. G. P., Novel processing of foam ceramics. Mat. Res. Soc. Symp. Proc, 1995, 371, 279-284.

30. Gu, Y., Liu, X., Meng, G. and Peng, D., Porous YSZ ceramics by water-based gelcasting. Ceram. Int, 1999, 25, 705-709.

31. Peigney, A., Laurent, Ch., Dumortier, O. and Rousset, A., Carbon nanotubes $-\mathrm{Fe}-\mathrm{Al}_{2} \mathrm{O}_{3}$ nanocomposites. Part I : influence of the Fe content on the synthesis of powders. J. Eur. Ceram. Soc., 1998, 18, 1995-2004.

32. Laurent, Ch., Peigney, A. and Rousset, A., Synthesis of carbon nanotube- $\mathrm{Fe}-\mathrm{Al}_{2} \mathrm{O}_{3}$ nanocomposite powders by selective reduction of different $\mathrm{Al}_{1.8} \mathrm{Fe}_{0.2} \mathrm{O}_{3}$ solid solutions. J. Mater. Chem., 1998, 8, 1263-1272.

33. Bacsa, R. R., Laurent, Ch., Peigney, A., Bacsa, W. S., Vaugien, Th. and Rousset, A., High specific surface area carbon nanotubes from catalytic chemical vapor deposition. Chem. Phys. Lett., 2000, 323, 566-571.

34. Peigney, A., Coquay, P., Flahaut, E., Vandenberghe, R. E., De Grave, E. and Laurent, Ch., A study of the formation of singleand double-walled carbon nanotubes by a CVD method. J. Phys. Chem. B, 2001, 105, 9699-9710.

35. Dai, H., Rinzler, A. G., Nikolaev, P., Thess, A., Colbert, D. T. and Smalley, R. E., Single-wall nanotubes produced by metalcatalyzed disproportionation of carbon monoxide. Chem Phys. Lett., 1996, 260, 471-475.

36. Hafner, J. H., Bronikowski, M. J., Azamian, B. K., Nikolaev, P., Rinzler, A. G., Colbert, D. T., Smith, K. A. and Smalley, R. E., Catalytic growth of single-wall carbon nanotubes from metal particles. Chem. Phys. Lett., 1998, 296, 195-202.

37. Kong, J., Cassell, A. M. and Dai, H., Chemical vapor deposition of methane for single-walled carbon nanotubes. Chem. Phys. Lett., 1998, 292, 567-574.

38. Cassell, A. M., Raymakers, J. A., Kong, J. and Dai, H. J., Large scale CVD synthesis of single-walled carbon nanotubes. Phys. Chem. B, 1999, 109, 6484-6492.

39. Cheng, H. M., Li, F., Sun, X., Brown, S. D. M., Pimenta, A., Marucci, A., Dresselhaus, G. and Dresselhaus, M. S., Bulk morphology and diameter distribution of single-walled carbon nanotubes synthesized by catalytic decomposition of hydrocarbons. Chem. Phys. Lett., 1998, 289, 602-610.

40. Colomer, J. F., Bister, G., Willems, I., Konya, Z., Fonseca, A., Van Tendeloo, G. and Nagy, B. J., Synthesis of single-wall carbon nanotubes by catalytic decomposition of hydrocarbons. Chem. Commun, 1999, 1343-1344.

41. Li, Y., Kim, W., Zhang, Y., Rolandi, M., Wang, D. and Dai, H., Growth of single-walled carbon nanotubes from discrete catalytic nanoparticles of various sizes. J. Phys. Chem. B, 2001, 105, 11 424-11 431.

42. Kitiyanan, B., Alvarez, W. E., Harwell, J. H. and Resasco, D. E., Controlled production of single-wall carbon nanotubes by catalytic decomposition of $\mathrm{CO}$ on bimetallic Co-Mo catalyst. Chem. Phys. Lett., 2000, 317, 497-503.

43. Su, M., Zheng, B. and Liu, J., A scalable CVD method for the synthesis of single walled carbon nanotubes with high catalyst productivity. Chem. Phys. Lett., 2000, 322, 321-326. 